\title{
THE USE OF SYSTEMS THINKING, SYSTEMS PRACTICE, TO ELICIT THE EFFECTIVENESS OF CANCER SUPPORT SERVICES IN THE SOUTHWEST OF ENGLAND
}

Gary Evans, Senior Academic in Sport Management, Bournemouth University, UK, Layne Hamerston, Managing Director, Living Well and Active, Southwest of England, UK, Lynn Cherrett, Lead Cancer Nurse, Poole NHS Trust, Dorset, UK, and Debbie Sadd, Principal Academic in Leadership and Strategy, Bournemouth University, UK.

\begin{abstract}
This article summarises findings of a systemic analysis of Living Well and Active's coordination and delivery of physical activity, health and well-being interventions for those living with cancer in the Southwest of England. The 16-month analysis and contributed to by cancer charities, consultants, healthcare professionals, local government officers, patients and physical activity health and well-being deliverers. While the findings proved there were pockets of good practice such as interventions delivery, organisations were found to be operating in a fragmented way, were resource starved and struggling to make sense of the top-down imposed healthcare policy changes. It meant the cancer referral process only captured 1:10 cancer survivors who might be on their pathway to normalisation. However, participants' conceptualised a different cancer referral process and a hub of practice similar to Living Well and Active to lead physical activity, health and well-being interventions, to improve the 1:10 cancer referral process.
\end{abstract}

Keywords: collaborators, deliverers and service-users, cancer support services, delivery chain, the hub of practice, interventions, systemic analysis, physical activity, referral process and virtual-paradigm methodology.

\section{INTRODUCTION}

Since 1997, consecutive British governments have recognised the intrinsic value of sport, physical activity, health and well-being to the nation's health and fitness. However, it was David Cameron's Conservative-led Government who finally prioritized these activities in their document Sporting Future: A New Strategy for an Active Nation (HMG, 2015, pp.2632). This top-down policy document set out the then Government's sport, physical activity, health and well-being policy objectives that Teresa May continued with as the Conservative Party nominated successor to David Cameron, with relevant Government Departments and funded quangos expected to align their organisational objectives to help achieve the physical activity, health and well-being policy objectives. It is clear reviewing the document that much of the emphasis on physical activity, health and well-being were stimulated by the earlier UK Chief Medical Officer's Guidelines (CMO, 2011) designed to reduce the $28 \%$ of the UK population who are considered inactive. Inactivity is defined by the CMO as doing less than 30 minutes of moderate intensity activity per week, and then the cost of that inactivity on the National Health Service because of related illnesses and wider implications of that inactivity on the nation's general health and fitness. Two other documents that seemed to trigger the Government's determination to tackle and reduce the nation's inactivity is Moving More, Living More (HMG, 2014) because of the costs of inactivity, and the Public Health England document Everybody Active, Every Day (PHE, 2014) and its four themes of: active society, moving professionals, active environments, and moving at scale. 
Sporting Future (HMG, 2015) then provides the policy framework and objectives to tackle and reduce the nations inactivity and how sport might respond to the framework through delivering regular exercise opportunities and promoting changes to people's lifestyles. Sport England, the UK Government's funded organisation granted autonomy to lead the delivery of sport and physical activity in England, with similar subsidiaries in Scotland, Wales and Northern Ireland, published its document Towards an Active Nation (SE, 2016, pp.18-19) in direct response to the Government's physical activity, health and well-being policy objectives. The document directs how the English Sport System will alter its focus to deliver future sport and physical activity interventions to society. Interestingly, the document also provides for special populations, target groups, as well as the general population. People who fall into this category are those living with cancer, the disabled, people diagnosed with diabetes, obesity or heart conditions and inactive children, and those with mental health problems. The people living with cancer were the focus of this research that concluded in 2017 and its systemic inquiry into the effectiveness of physical activity, health and well-being interventions for those living with cancer in the Southwest of England.

\section{METHODOLOGY}

The systemic analysis was guided by the virtual paradigm methodology Circumstances, Values and Viewpoints, Activities and Means (CVAM) (Castle, 1999). CVAM was originally selected after preliminary discussions with potential organisation such as Living Well and Active and respondents' who offered verbalisations that prompted the need to data capture in the objective, subjective and radical paradigms of practical thought. This suggested a multiparadigm methodology would be best suited to such data capture and promoted a systems search for a claimed multi-paradigm methodology. CVAM and Total Systems Intervention (TSI) (Flood and Jackson, 1991) were located and after a review of their methods the Principle Inquirer (PI) recommended Castle's (1991) CVAM. CVAM seemed to offer more robustly designed methods such as Mapped Resolutions of Activities and Means (MRAM), and certain criticisms were found in the literature (Midgley, 2000; Mingers, 1997) about Flood and Jackson's TSI, such as lacking any proper philosophical and theoretical grounding and limited guidance on how to use substitute methods as part of a systems analysis. CVAM addresses the latter because each method is mapped onto the CVAM Process Framework (Castle, 1998b) to reveal which steps are complete for each paradigm and which are not, plus points to discrepancies for improvement which stimulate systemic learning. The 'Cs' of CVAM are the circumstances, external forces, impacting on the system's boundary of an organisation (or organisations), and the 'Vs' the viewpoints of the system actors on what should be done about the circumstances and other internal improvements to the organisation. The 'As' are the activities designed by the systems actors to address the circumstances and can be processes or systems, and the 'Ms' are the means, resources, to operationalize the activities to tackle the Cs. To reiterate, CVAM offers methods to guide inquiry into the $\mathrm{C}, \mathrm{V}$, $\mathrm{A}$, and $\mathrm{M}$ imperatives. It is fair to say CVAM is a complex methodology to use, possibly a sledgehammer to crack a nut; however, it does provide for an in-depth analysis into the phenomenon of interest.

The use of CVAM for this analysis can be further justified as a Checkland and Scholes (1990) Mode 2 deployment to guide better interactions and more naturalistic inquiry with cancer survivors, charities, healthcare professionals and physical activity, health and wellbeing deliverers, to make sense of what was going on and trigger debate about change. A further complexity of the research was the apparent need to collaborate with the Living Well and Active (LWA) organisation and its partners to access the organisations and respondents in the cancer pathway, to inform the analysis. This meant LWA was, in effect, the gatekeeper 
that protracted the University Ethics and Research Governance process and time it took to access organisations and respondents. However, the CVAM findings were worth the time and effort.

\section{CIRCUMSTANCES}

The circumstances are positive and negative forces impacting on the system's boundary of an organisation, or organisations, at one level of recursion above the organisation (Castle, 1998b). An organisation has no control over such forces impacting on its boundary, but usually has to respond to the forces to ensure its future purposefulness and viability.

The recurring circumstantial themes that surfaced through the data, as prioritized by the collaborators, deliverers and service users respondents', were: society's awareness about cancer in general, National Health Service policy changes, an ageing UK population, healthcare services into the community, patients ownership of their illness and health, the populations awareness about the importance of physical activity, changing attitudes of healthcare professionals, and switching of Health Services resources to supporting the survival agenda rather than palliative care. The respondents' recognised society's awareness about cancer had changed compared with 10 years ago, with people much more willing to talk about their cancer, mostly because of social media and being able to connect with other cancer sufferers who could not physically get together due to access barriers. Typical access barriers cited here were affordability, distance and lack of mobility, and family and work time pressures. However, connecting virtually with patients of the same mind-set had given others the courage and confidence to share their experiences. Unsurprisingly, the collaborators' of the purposive sample were found to be knowledgeable of the National Health Service healthcare policy changes and cited the Public Health England document Everybody Active, Every Day (PHE, 2014) that was targeted at public sector organisations and its four themes, and the more recent National Health Service document Cancer Healthcare for the Future (NHS, 2015) and what it conceptualises as the cancer survivorship agenda. Cancer Healthcare for the Future calls for supporting people living with cancer to manage their own condition, health and well-being. At least two collaborators' also referred to the National Health Service document A Five Year Forward View (NHS, 2016) and its call for more involvement by $3^{\text {rd }}$ sector organisations in helping to bridge some of the perceived gaps in supporting patients' needs along the cancer care pathways. A Five Year Forward View also emphasises the survivorship agenda so patients self-manage their follow-up pathway and to move away from the traditional routine appointments to appointments when patients believe they need a consultation. The Five Year Forward View imperatives then are around equipping individuals with the necessary skills and knowledge to end their treatment through selfmanagement, to assist them live well with and beyond cancer.

The UK's ageing population was argued as a significant circumstance change and how cancer had then become a long-term condition. This had resulted in over stretched treatment centres and clinics, so much so collaborators' pointed to patients being discharged from acute services earlier and being told to self-govern their health and recovery. The policy move to patient-triggered follow-ups as opposed to regular appointments every 3 months was reiterated, thus a patient's own symptoms and knowledge would trigger an event back into hospital. What respondents' themed as this person-centred support acknowledged cancer survivors needed access to physical activity, health and well-being information at the point of diagnosis on the cancer referral process (see Fig 1) through to their long-term physical activity, health and well-being adherence. This meant cancer support services needed to sit alongside diagnosis and acute care, and then onto interventions and adherence, as illustrated 
in Fig 1. Fig 1, is the collaborators', deliverers' and service-users' conceptualisation of the cancer referral process validated during a CVAM workshop (see p.11) because no such model existed. However, one collaborator, a cancer care and end of life specialist, pointed to how the whole story of cancer was starting to change as more survivors were living with and beyond cancer. He further argued that different cancers had different outcomes and that there was good, middle and bad ground prospects for cancer survivors nowadays than yester year.

The Government's policy intention to switch healthcare services into the community environment and away from the clinical environment was a noticeable theme in the circumstances data. Respondents' interpreted this as a Government initiative to achieve efficiency savings, irrespective of the impact on survivors because of them having to take ownership of their health, recovery and well-being. Respondents' further interpreted this as less dependency on clinical services and the costs associated with providing clinical services. What the respondents' had themed as the populations changing awareness about the importance of physical activity, health and well-being featured strongly in the data. The public were felt to be far more health conscious and likely to engage in physical activity, health and well-being interventions than 20 years ago, even though engaging with these interventions was considered expensive. The importance of physical activity, health and wellbeing was felt to be slowly reaching cancer survivors, albeit the numbers who were engaging remained a small percentage of those actually diagnosed with cancer in the area of interest. There was some evidence in the data to suggest the public's awareness of physical activity and the message getting through to cancer survivors was because of the changing attitudes of healthcare professionals. Health professionals were more likely to refer the public and survivors to deliverers of physical activity, health and well-being interventions than previously, although the information needed to do this was considered at best patchy. The final circumstances theme prioritized by respondents' that overlapped to some extent with 'patients' ownership for their recovery and health', was the theme of switching resources to support the survival agenda rather than palliative care. A number of the respondents' had noted more of the National Health Service investment being diverted to survival as opposed to palliative care. This had been interpreted as a positive signal for cancer survivors because the Health Service seemed to have the view cancer could be beaten in some cases rather that what people die of. The counter argument though was that other cancer support services were not best prepared for the switch in investment. The implication of the patient ownership circumstance was best summed-up by a collaborator respondent:

“I think we've become a bit too precious about cancer and that may be a very politically charged thing to say... I think we need to be saying that cancer is a horrible disease for some, but it's also very treatable disease in others... I think it's about getting ownership, the patient owning their condition and being more responsible for their life choices..."

\section{VALUES AND VIEWPOINTS}

The values and viewpoints are the verbalisations of respondents on the circumstances impacting on the system's boundary of an organisation, or the internal process that are hindering the performance of an organisation (Castle, 1998b). It is important when capturing respondents' values and viewpoints on the internal processes of an organisation that all values and viewpoints are evidenced to prevent spurious claims of underperformance in the organisation. Through evidencing the internal processes that are hindering performance in this way brings order and control to data capture and how respondents prioritize the data thereafter. When it comes to the circumstances respondents are granted freedom to be 
creative and innovative with their values and viewpoints to tackle the circumstances impacting on the system's boundary of an organisation. It is quite possible though some circumstances are impacting on an organisation that it cannot find a direct solution for, thus is becomes a process of risk management for an organisation.

All respondents' were cognisance of the public's increased awareness of cancer in society and the potential demand that creates for their services. Several collaborators and deliverers expressed concern about their actual reach and survivors understanding what they offered as interventions or services. Similarly, viewpoints were captured on the National Health Service referral process because collaborators' and deliverers' contested whether healthcare professionals interacting with potential patients needed to understand their service offer and it was challenged whether this was the case. A deliverer was more critical, because even if healthcare professionals had the information and training would they actually refer patients to the physical activity, health and well-being cancer support services? The collaborators' were certainly knowledgeable of the National Health Service policy changes such as the survivorship agenda, increased involvement of the $3^{\text {rd }}$ sector in the cancer pathways and the Health Service investing more into the community environment as opposed to the clinical environment. However, this had caused a systems leadership vacuum, confused the cancer pathway partnerships and left the responsibility of patient recovery to patients with limited skills and knowledge.

The LWA organisation had recognised this and through coordinating cancer support services had become by default the leadership organisation for the delivery of physical activity, health and well-being interventions for those living with cancer in Dorset. The sense of goodwill towards LWA from collaborators', deliverers' and service users' was incredibly strong because of this. How LWA encouraged, engaged and connected people and organisations was applauded too, as was how LWA brought organisations with similar objectives together for the benefit of people affected by cancer. As a consequence, many organisations were found to have linked and developed relationships with LWA to benefit their service users, so direct relationships than simply signposting, referring or recommending LWA. The LWA organisation was also praised by respondents' for how it resourced its partnerships and for encouraging other deliverers to join its network of partner organisations. LWA's effectiveness in the cancer pathway was enthusiastically described by a service user:

'It's connecting people together... showing people that they're other things out there. It's where you can find anything out, and the emails that come out regular are telling you all these things. It's just fantastic, and the information you get, it's just phenomenal..."

It was fairly clear in the data collaborators' and deliverers' were aware of the UK's ageing population, just how they intended to modify their interventions to satisfy the needs of this population was limited in the data. In contrast, the contemporary sport and physical activity sector had already modified its offers to satisfy the preferences and needs of this perceived growth market. The same was true for the switch of healthcare services into the community because of the reconfigurations such change demanded causing a state of flux. Such strategic reconfigurations required the redesign of organisations, different governance and leadership arrangements, the building of new relationships and realigning of resources. This meant it was difficult for some collaborators' and deliverers' to fathom out how they connected to the reconfiguring healthcare services at that juncture in time. 
The data was far richer for patients' ownership of their illness and health because collaborators', deliverers' and service users' were highly critical of the patient referral process. If patients were to assume ownership of their recovery and health, to self-govern and self-manage, then the cancer services delivery chain needed to do this from the point of diagnosis to adherence (see Fig.1).

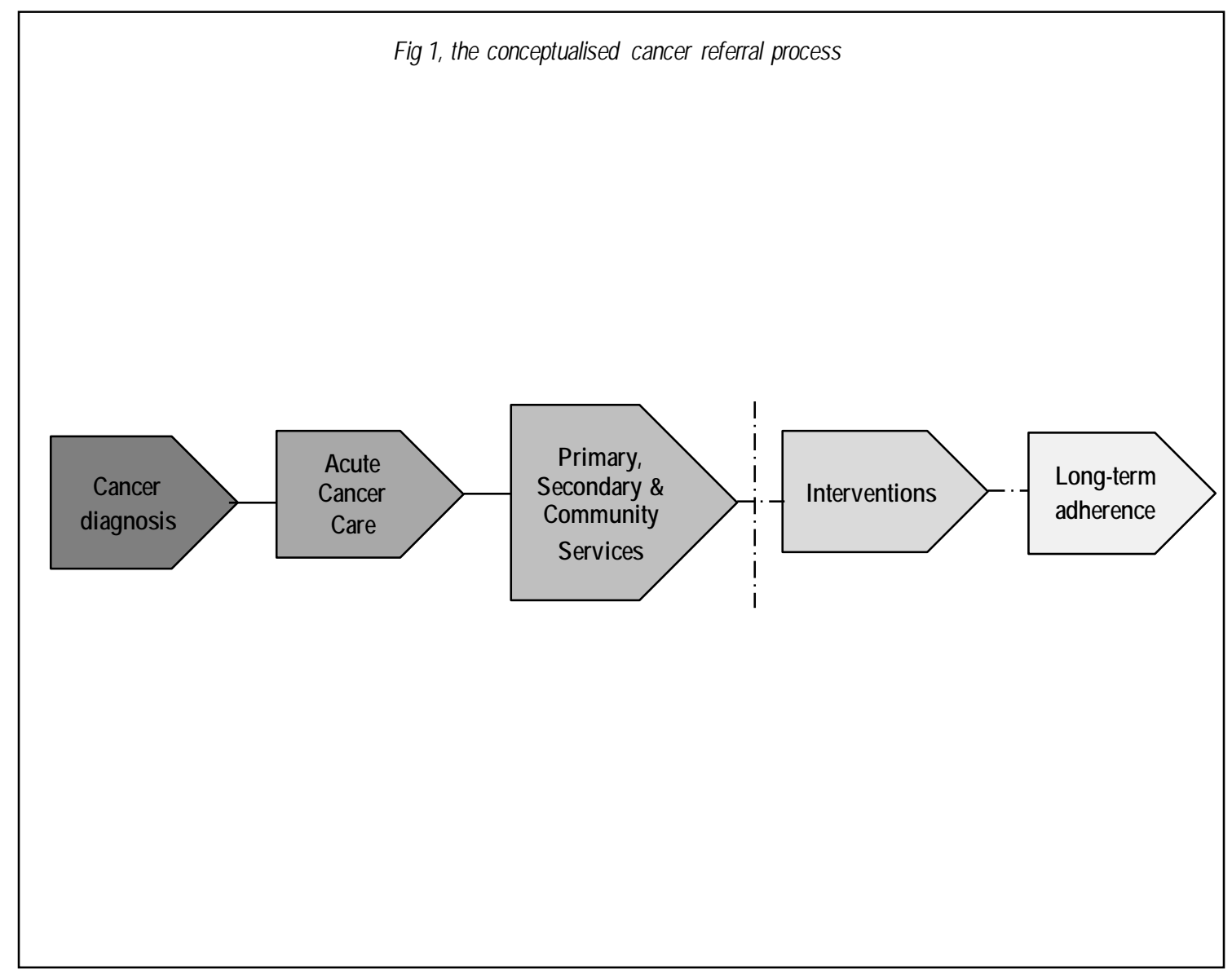

The actual referral process inadequately did this, thus of the approximate 5,000 cancer survivors in the area of interest, the area in the Southwest of England, less than 500 had entered the cancer pathway designed to help them normalize after their cancer diagnosis and treatment. This is illustrated by the Fig 1 pecked line pinpointing where collaborators', deliverers' and service-users' feel the referral process was ineffective. So, depending on where patients received their acute care in the area of interest, they may or may not be referred to a cancer pathway. Put simply, a 1:10 chance they would be referred to a cancer pathway such as the interventions coordinated by LWA.

The importance of engaging with other patients deliverers' considered a critical success factor to intervention adherence, and personalizing the intervention for the patient and encouraging the patient to participate with their supporter. So, patients understanding what is available to participate in, being able to participate with others living with the same disease or with a supporter, deliverers argued had a strong motivational element to it. Making patients aware of what was available to them and giving them choice was also considered important by deliverers', because patients were much more likely to participate in an intervention if they had choice. The deliverers' stressed though a very hit or miss referral process as it stood. 
The public's changing awareness about the importance of physical activity and health was a circumstance recognised by collaborators' and deliverers'; however, the challenge for them was bringing people and organisations together to individualize the interventions for each and every patient. The intention here was rallying people and organisations around the common cancer cause because of the 1:10 referral process chance. A more positive message evident in the data was the changing attitudes of the healthcare professionals that had helped with the awakening of the public's and survivors to the need for regular physical activity. The collaborators' and delivers' were upbeat on this circumstance and found to have provided information and training on physical activity, health and well-being interventions they provided, and LWA had also delivered some events targeted at healthcare professionals. However, the physical activity, health and well-being sector was perceived by healthcare professionals to be complex and difficult to understand due to the various organisations involved in the sector. Collaborators' and deliverers' argued it might be too much to request healthcare professionals to give advice to patients on where they should go to access physical activity, health and well-being interventions. Perhaps this was an explanation for the low referral rate, plus healthcare professionals seemed to be under a lot of pressure in their clinical environments. It would certainly make their jobs easier if all they had to do was to refer patients to one organisation such LWA. All the participants' reflected very positively about how effective LWA was at keeping in touch with survivors, keeping them informed of what was going on and how easy it was to navigate the website to review activities on offer. LWA was also rated very highly by service users' on the ease of access to information and its very informative Discovery Days. It was argued as being in the strongest position to vet potential deliverers of physical activity, health and well-being interventions as well. For the referral process to be more workable from the healthcare professionals' perspective, the process had to be simplified.

The respondents' reflected positively on the switching of Health Service resources to supporting the survival agenda rather than palliative care. They viewed it as a social entrepreneurial opportunity to extend physical activity, health and well-being interventions to other conurbations of the area of interest. They felt it stimulated partnerships in the interest of those affected by cancer to vary the range of physical activity, health and well-being offers to survivors. Respondents' further interpreted this as clinical services, acute services, focusing solely on what service they do and leaving other elements of the cancer support services to more specialised cancer care charities and organisations such as LWA. A verbalisation of a deliverer reiterated the success of LWA at rallying services:

"I did an event with them at the University and it was fantastic... because there were lots of people there as well... all the different people that they've got involved and the different partners, I just think it’s amazing...”

\section{ACTIVITIES}

Activities are the designed processes and systems, the implemented processes and systems, to tackle the circumstantial forces that are impacting on the system's boundary of an organisation and awakened it to action. The processes and systems in response to the circumstances impacting on the system's boundary of an organisation are usually designed by the systems actors of an organisation and prioritized and validated by them before implementation. Once prioritized and validated each activity then becomes a strategy of the organisation. In accordance with the logic of CVAM (Castle, 1999), the only true strategy of an organisation is one that deals with the external forces, thus is a child of the environment (Castle, 1999). 
It is important to point out the data was very rich in terms of collaborators' and deliverers' activities they had designed, modified or implemented to address the circumstances. Their activities as processes or systems were the physical activity, health and well-being interventions for those living with cancer in the area of interest. Some of their interventions were referred to as programmes and varied in length between 6 to 12 weeks, with some survivors having the opportunity to continue with their programme once the initial 6 to 12 week programme had completed. What became clear from the systems analys is of collaborators' and deliverers' activities was how different they were to the suggested activities indicated in the Sport England document Towards and Active Nation (SE, 2016, pp.18-19). The programme theory of the collaborators' and deliverers' activities pointed to a different logic than Towards and Active Nation and interestingly, how survivors had been encouraged in co-designing new activities. Their co-designing of activities had contributed to fully subscribed activities and that achieved high adherence levels for all deliverers'. Such high subscription and adherence levels were very different to the contemporary Sport and Physical Activity sector that tended to have lower subscription rates and adherence levels. The high subscription and adherence levels were also found to be as a result of how long collaborators' and deliverers' had been offering their activities in the cancer pathway. For some collaborators' and deliverers' they had been offering their activities for 8 years, as was the case for LWA. All this meant collaborators' and deliverers' had learnt how to satisfy the needs of the survivors, and commissioned independent research to prove that, plus their effectiveness at delivering activities and survivors satisfaction with their activities.

Whilst the programme theory of collaborators' and deliverers' activities was different to that indicated in Towards and Active Nation, their programme theory aligned better to the physical activity and well-being literatures. From the physical activity research of Chen et al (2015), they demonstrated that a walking-based exercise programme had a positive effect on decreasing survivors' anxiety, and Wenzel et al (2013) that a home-based walking intervention helped reduce the emotional distress of survivors receiving treatment for prostrate, colorectal and other solid tumours. Bernardo et al (2010) had also called for walking-based programmes for women undertaking breast cancer treatment, and Brown et al (2013) for uterine cancer survivors to improve their lower limb function. Jeff and Huit (2015) proved that patients with head and neck cancers achieved improved movement through stretching exercises, and Gautam et al (2011) that the benefits of stretching and exercise helped in reducing lymphoedema in breast cancer survivors. From the research of Cormie et al (2013b), they highlighted significant improvement in muscle strength and endurance in women with breast cancer, and Katz-Leurer (2010) that aqua lymphatic therapy reduced swelling post-breast cancer procedure. Midtgaard et al (2011) demonstrated that a multimodal exercise intervention of high and low intensity training significantly reduced levels of depression in cancer survivors, and Livingston et al (2015) that exercise interventions had a positive effect on the emotional well-being of prostate cancer survivors. Irwin et al (2015) argued that exercise reduced pain and improved survivors' strength, as did Nordic walking from the research of Fields (2016). McNeely et al (2008) had earlier described the association between physical activity and pain reduction, and Saar et al (2010) that step aerobics improved the bone mass density of survivors. Winters-Stone et al (2011) achieved similar results when combined resistance and impact training was prescribed to spinal injury survivors.

What was evident from the comparative analysis against the literature is that some of the activities, interventions, detected were offered by collaborators' and deliverers' or LWA. However, further inquiry is necessary to elicit why other physical activity interventions are 
not, for example, no specialist deliverers in the area of interest, lack of resources or no survivor interest. Table 1, summarises the collaborators' and deliverers' physical activity, health and well-being interventions analysed, otherwise, the need to individualize or personalize an intervention because of a cancer reiterated in the literature.

Table 1, collaborators' and deliverers' physical activity, health and well-being interventions

\begin{tabular}{|l|l|l|}
\hline Physical activity & Health & Well-being \\
\hline Altitude adventure & Bikram yoga & A'Courts \\
\hline BH Live & Boots chemist & Advice training \\
\hline BHF Bike Ride & Eat well & Coffee mornings \\
\hline Bournemouth Bay run & Gardening for health & Boost \\
\hline Festival of running & Hair and beauty & Discovery talks \\
\hline Exercise referral programmes & Health and well-being clinic & LWA and LWA drop-ins \\
\hline Moors Valley & Healthy home checks & FAB \\
\hline Nordic walking & Home energy & Feel good \\
\hline Pink champagne & MOTs & Freedom and beyond for women \\
\hline Poole park & Move more & Great escape initiative \\
\hline Poole park volunteering & NHS & Mindfulness and relaxation \\
\hline Table tennis and ping pong & Pamper evenings & Motivational talks \\
\hline Tai chi & Quick links & Moving forward \\
\hline Tri-active Poole park & Sleeping well & Paul's story \\
\hline Tripudio & & Penny Bonn \\
\hline Swimming & & Raising voices \\
\hline Walking football, netball & & Self-esteem course for women \\
\hline Walking4softies & & SHINE \\
\hline & & Thrivership events \\
\hline & & Winter will power \\
\hline
\end{tabular}

An observation of the comparative analysis was the programme theory as it related to collaborators' and deliverers' well-being and mindfulness interventions. Well-being and mindfulness were not found to be particularly embedded in the programme logic of collaborators' and deliverers' interventions. This maybe because well-being and mind fulness were misunderstood or just omitted altogether from the logic of collaborators' and deliverers' interventions. This might be due to the complex and often contradictory nature of well-being and mindfulness theories, thus an inexperienced practitioner would not know how to embed well-being and mindfulness theories into the programme logic of an intervention.

From the research of Seedhouse (1995), Chen et al (2013) and King et al (2014), they warn of the definitional discourse surrounding well-being and mindfulness theories which might further complicate design for practitioners. But, useful explanations and insights into wellbeing are offered by Chen et al (2013), King et al (2014), Lucas and Diener (2015) and the Department of Health (DoH, 2013). The DoH (2013) further explains well-being as objective, subjective and hedonic, and Weich et al (2011) as eudemonic and corresponds with the psychological and mental well-being of an individual. From the research of Self et al (2012), they explain the importance of social and supportive relationships across an individual's lifespan and how vital this is to an individual's self-reporting of health and health behaviours. This would certainly assist in understanding the effectiveness of an intervention and what improvements might be necessary to benefit service-users. The psychological factors such as adapting, goals and coping strategies are useful insights from the research of Diener (1999) and Lukas and Diener (2015), and the importance of emotional well-being and happiness 
from the research of Sanne et al (2012) and Diener and Chen (2011). Lukas and Diener (2015) also point to the role of personality traits, and the useful insight of Rodriguez et al (2013) and Schroevers et al (2008) that re-engagement with meaningful goals is key to an individual maintaining control in their life, including acute phases of illness and recovery. Interestingly, Schickler (2005) offered an earlier counter-argument that positive well-being can still be achieved independent of health and despite chronic illness, in other words, it might not be necessary to embed well-being and mindfulness into the programme logic of an intervention. Schickler further argues that well-being is always present so more a case of interpreting the positive and negative influences on an individual's well-being. To some extent Sanne et al (2012) would contest Schickler's position because they explain the importance of well-being during physical illness, and Barak's (2006) insight that an individual with a base-line well-being level is more likely to recover and survive a serious illness such as cancer. From the research of Diener and Chen (2011), they explain the significant effect between happiness and longevity, albeit both might alter depending on the type of disease and level of disease progression experienced by an individual, such as cancer. Therefore, this overview of the key well-being and mindfulness literature does emphasize the need to understand the relevant theories and embed them into programme design. The importance of well-being and mindfulness was certainly recognised by service users, as highlighted by one service user:

'If you were diagnosed, you'd think I've got to go hospital, I've got to have this treatment, I can't do anything... now I think they try and tell you that it's [cancer] just a hiccup. It's just something, get on with your life, and get on with what you want to do... it makes your head feel better as well as your body..."

The importance of well-being and mental considerations for programme designers cannot be overestimated as far as the PI is concerned. He contests the actual ordering of words should not be physical activity, health and well-being, rather well-being, health and physical activity. There is strong evidence in the data that to trigger behavioural and lifestyle changes interventions must start with the mental state of the service-users and getting this correct before progressing to health considerations and then possibly individualized physical activity. Returning to the arguments around knowledge and understanding necessary to deliver effective interventions in a cancer pathway, the verbalisation of a collaborator indicates the time it takes to build-up cancer care experience:

"The organisation, as I say, is 21 years, although we might amend that [service] accordingly... As an individual, I have been interested in providing a service for patients who are living with cancer for probably 10 years...”

\section{Means}

Means are the resources necessary to operationalize the activities, to tackle the circumstances (Castle, 1998b). The resources are unique to each process or system and in the broadest sense such as equipment, facilities, information technology, people, training and development and various types of information for patients and healthcare professionals. The PI has consistently found from other systems projects that rarely do resources get reordered to help organisations resource their strategies, hence, little surprise organisational objectives do not get achieved or only partially achieved.

It is fair to say all respondents' offered verbalisations on resources, with deliverers' verbalisations most noticeable in the data. Whilst is was proved all interventions were fully 
subscribed and achieving adherence levels higher than the contemporary Sport and Physical Activity sector, to increase reach might require additional funding. The scaling-up which would happen was flagged as a concern, as was the physical activity, health and well-being message being diluted with any such scaling-up. This was especially so for the collaborators' and deliverers' who believed the LWA model could be extended to other health conditions such as cardiac, diabetes and obesity. They pointed to a loss of focus on the individual as well which remained critical for cancer survivors.

The changing face of the Health Service was considered a challenge for collaborators' because of its funding priorities, and how changes in national government exasperated both funding and prioritizing of services. Some collaborators' and delivers' were concerned about keeping the physical activity, health and well-being interventions momentum going as a consequence. They contested momentum would certainly stall if LWA disappeared. The collaborators' argued the direction of travel would dramatically halt too, because LWA was considered enthusiastic and got the challenge that people with health conditions had. LWA was also felt to be effective at getting health providers across the area of interest together and supporting providers tackling the survivorship agenda. Again, the Health Service initiatives, goals and targets it kept introducing caused service fatigue, and the Health Service failing to realise healthcare professionals cannot be experts in cancer support services as well as acute services. Such initiatives were felt to be causing too much strain and diluting what was considered an effective acute services provision.

The collaborators' and deliverers' constantly referred back to surviving the current financial climate and the fear it brought to bear on their organisations, for example, the physical activity, health and well-being Partners. How this might impact on LWA and the support it received from its Partners. Further, what LWA must continue to do to maintain its ethos of trying to improve patients' healthcare, and not lose sight of that if it became a larger entity. The collaborators' other recognised danger here was LWA becoming detached if too large an entity, too administrative, because it had to be a very practical and responsive organisation to meet service-users' needs. They expressed concerns caused by confusion to the public and healthcare professionals around the different services that were available, mainly because GPs (doctors) and the public are constantly bombarded with conflicting service offers which, coincidently, was viewed as duplication and a waste of scarce resources. A general reduction in funding though was a fear all collaborators' had, even though some were specialist charities with dedicated fundraising departments. A service-user made a startling observation of LWA's Partnerships the PI would have expected from one of the more knowledgeable collaborators', as follows:

"I guess they've [Living Well and Active] got to keep their partners, to keep them interested... there's probably a limit of partners that beyond which you can't manage it and its gets unmanageable... perhaps you have subcategories of partners that might be more beneficial to certain conditions...”

Their perceived effectiveness of LWA stimulated much discussion, so much so the PI facilitated a 2 day exploratory workshop to elicit from respondents' what a physical activity, health and well-being hub or practice for those living with cancer might look like and do differently to LWA. To fully explore what a hub of practice might look like and do differently, the subjective paradigm of the CVAM Process Framework (Castle, 1998b) guided the systemic 2 day inquiry. Fig 2 summarises what the respondents' hub of practice might look like in terms of its specific focus. 


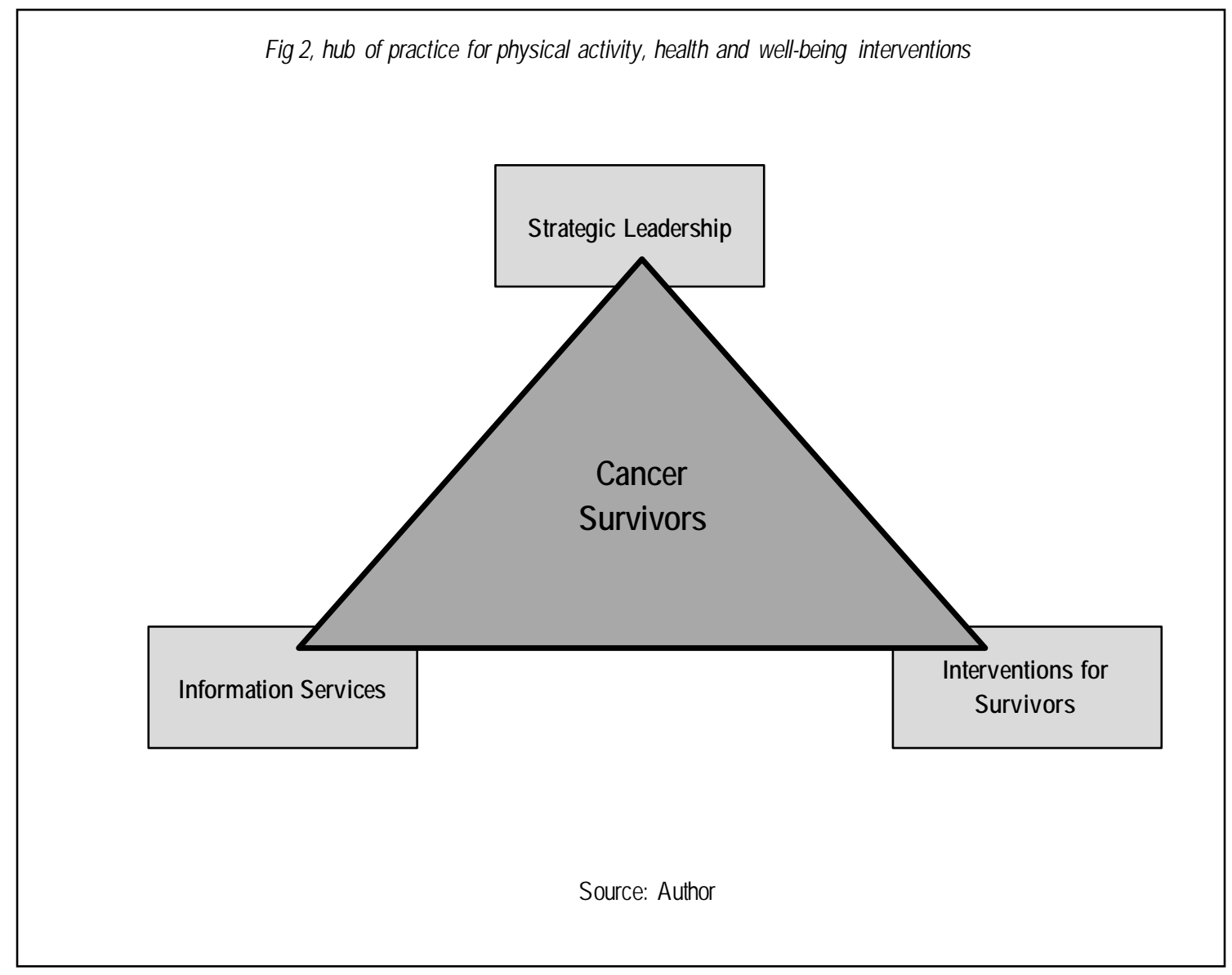

Fig 2 is quite fundamental from the PI's perspective and is subject to on-going work at the time of this submission. In short, the collaborators', deliverers' and service-users' validated what the hub of practice should do under strategic leadership as: governance, recruit new partner organisations, coordinate offers and interventions, networking, policy advice, funding and broker, and relationship management. For information services respondents' validated: one-stop solution, events and conferences, discovery days, training of healthcare professionals, quality assurance, impact assessment, and e-resources and website services. They validated the following for interventions for survivors: health offers, well-being interventions, physical activity offers, access to informal sport and recreation, mindfulness support, individual programme design, adherence, and normalisation strategies. The collaborators', deliverers' and service-users' emphasized the hub of practice, as a centre of excellence and best practice, is the strategic organisation for physical activity, health and well-being interventions for those living with cancer in the area of interest. It is intended as an organisation healthcare professionals can turn to for advice, survivors for support and policy bodies such as the county commissioning groups (CCGs) and public health boards (PHBs) to access up to date research to inform their policy decisions. The collaborators', deliverers' and service users' asserted the hub of practice must be research driven to disseminate reliable and valid data on delivery and best practice to all those involved in the cancer pathways. A not-for-profit legal structure is favoured and perhaps hosted by a county sport partnership, charity or university. The hub of practice is the respondents' solution to tackle the circumstances and advance cancer care across the area of interest. They asserted it is a smart fit with Government's current healthcare policies, and the emphasis on the hub of practice being research driven was well-argued by a collaborator: 
'It needs to develop a research base, it needs to actually have evidence of how it's [Hub] delivering on that, how has it changed practice, have the Commissioners listened, have they brought into it... the most important is what evidence-base have we got that's actually changed anything with the patient and family..."

The collaborators', deliverers' and service-users' also extended Fig 1, the cancer referral process, to illustrate what they perceive as the cancers support services delivery chain (see Fig 2). They argue each link of the chain has different information needs to progress a service-user from diagnosis to long-term adherence, and a more effective solution to operationalize the hub of practice.

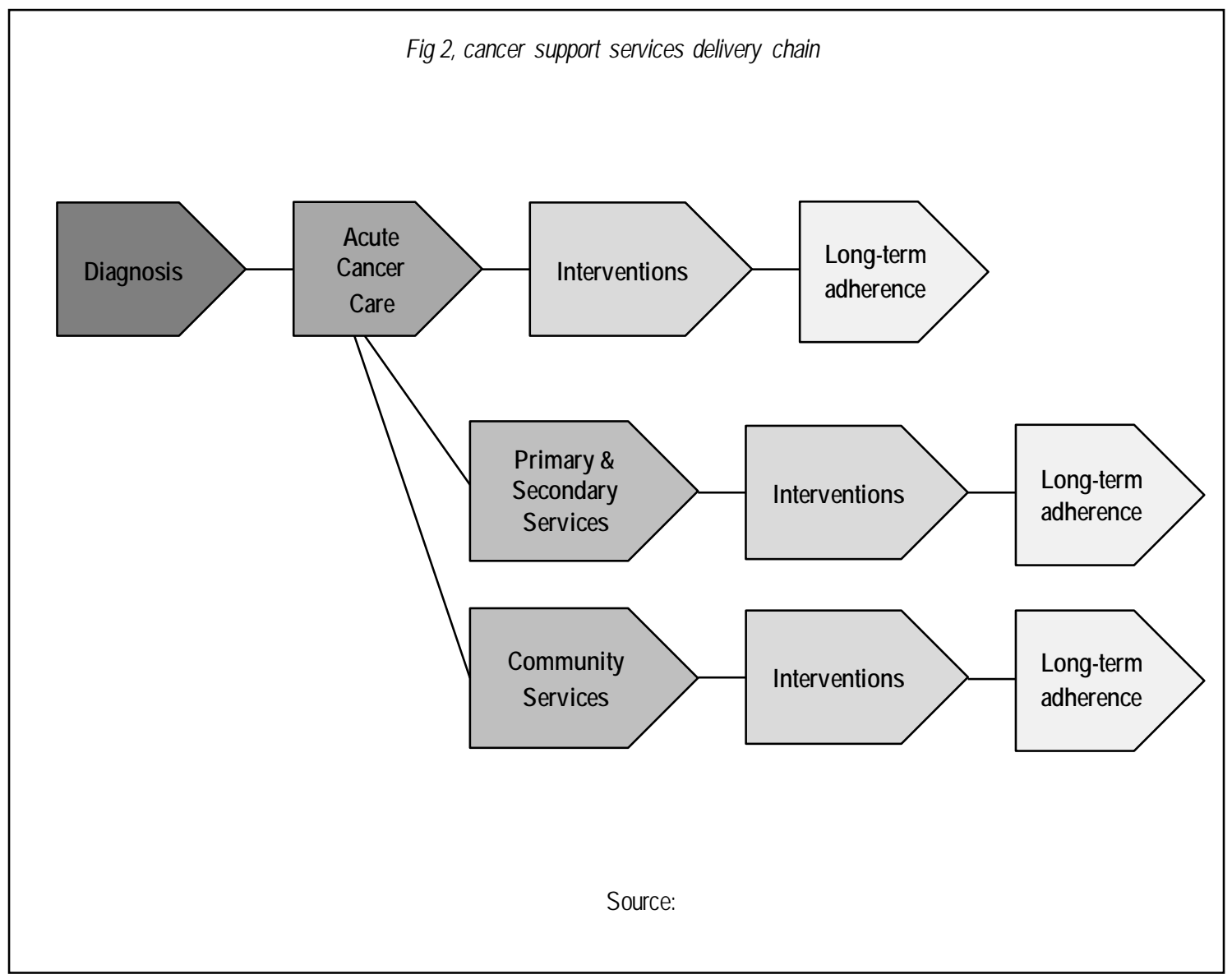

\section{CONCLUSION}

This systemic analysis into the effectiveness of physical activity, health and wellbeing interventions for those living with cancer in the Southwest of England concludes that these cancer support services cannot be considered as a system. At best, the cancer support services can only be described as a notional system, as theorized by Stowell and Welch (2012, pp.2526). There are various elements to suggest some purposeful activity; however, the elements were found to mostly function independently of one another and do not operate holistically. This meant detected emergent properties were not responded to in a meaningful way, and the hierarchy of activities, the levels of recursion, were not coherently structured. Because of the apparent lack of systems leadership and governance control was reduced to reporting back to funding agencies the numbers of service-users engaging in the cancer pathway interventions, and survivors' satisfaction with their intervention to stimulate continuous improvement. This 
meant control was limited to just two levels of recursion because of the disjoined nature of the cancer support services. On a more positive note, a systems boundary was proved as some sixty-three organisations were found to be engaging in the physical activity, health and wellbeing cancer support services, with several organisations aware of the existence of each other. In fact, some organisations had a long standing relationship of 8 years plus, thus their referral processes for service-user interventions were found to be integrated and mature.

The systemic analysis revealed the altering context for cancer support services and the very significant and complex change that was impacting on the system's boundary of organisations. This had been triggered by the new National Health Services policies focusing on survivorship and switching of more clinical services into the community environment, mostly for efficiency reasons, and to cope with the predicted rise in cancer occurrences in the UK. To some extent, this caused a state of flux for organisations engaged in the cancer pathway as they fathomed out how to reconnect to the emerging community healthcare environment. A fundamental finding of the analysis was the cancer support services referral process and the inadequacy of the process as it stood. It was proved that roughly $10 \%$ of potential service-users were actually being captured and supported on a cancer pathway to normalisation. This did not mean the referral process was failing as service-users subscriptions for interventions and adherence levels were higher than the contemporary Sport and Physical Activity sector. Rather, it was more a case of organisations not being joined-up because the referral process needed to commence at the point of service-user diagnosis through to adherence, as illustrated in Fig 1. If this happened then a dramatic upturn in the numbers of patients engaging in the cancer pathway could be expected, because the referral process barriers would be overcome between acute cancer care, primary and secondary care and community services.

A further discrepancy was revealed with the physical activity, health and well-being interventions in the cancer pathway as these were found to be different to the interventions suggested in the Sport England document Towards and Active Nation (SE, 2016, pp.18-19). There was possibly an over emphasis on formal sport when informal sport might be more appropriate for survivors. In fact, only one deliverer claimed their survivors had engaged in formal recreation and sport, although this deliverer was the exception and not the norm for service-users. In contrast, the physical activity, health and well-being interventions were better aligned to the physical activity literature, albeit not an extensive range of offers available to service-users and subject to further inquiry. However, what were considered as the well-being interventions were proved not to be well enough aligned to the well-being literature, particularly mindfulness and an area of improvement for intervention designers. This finding brings into question the programme theory in-use and logic of interventions and what designers were setting out to achieve with their interventions.

Some of the above improvements could be addressed by the hub of practice work undertaken by the collaborators', deliverers' and service-users' during the 2 day workshop. The collaborators', deliverers' and service-users' conceptualized and validated what they believed was the solution to improve the leadership of the cancer pathway and uplift the information and quality of interventions for survivors (see Fig 2). Their hub of practice was partly based on the successes of the LWA organisation and what they viewed as the natural evolution of LWA. The hub of practice was considered by collaborators', deliverers' and service-users' as a good fit with the current National Health Service priorities and promoted joined-up thinking for the future delivery of cancer support services, to become a more purposeful and viable system. 
The cancer support services delivery chain and hub of practice for physical activity, health and well-being interventions for those living with cancer in the area of interest were fundamental outputs of the analysis, in the view of the PI. These outputs helped to reshape his thinking and why to challenge the policy wording of physical activity, health and well-being, to well-being, health and physical activity. It is now clear the mind-set of the service-user must come first and then possibly the other imperatives. The findings of the systemic inquiry have also informed the following strategic pieces of work:

- Creation of an organisational methodology to assess the systemic impact of LWA;

- Continuing work to form a hub of practice for well-being, health and physical activity interventions for those living with cancer;

- PI appointed to the Strategic Delivery Group of LWA;

- Secured a $£ 4 \mathrm{k}$ funding bid to inquire into the referral processes of other organisations across the area of interest;

- Helped to win a £660k bid from Sport England to complete a systems analys is of its new Active Ageing programme.

Lastly, the CVAM (Castle, 1999) methodology is complex to use; however, the PI noted early on that to complete the analysis data needed to be collected and analysed from the three paradigms of practical thought. An alternative improvement tool in-use by the National Health Service might not have noticed this, plus have a predetermined sample frame of subjects to engage with. This sample mostly evolved as the analysis unfolded, and the way collaborators', deliverers' and service-users' attenuated the data would not have been repeated to the same standard as CVAM guided. How CVAM guided the workshop to conceptualize the delivery chain and hub of practice as well. Overall, the systemic analysis engaged collaborators', deliverers' and service-users' in a very different way and generated findings that are informing strategic projects at the time of this article, such as the Sport England, the UK Government's sponsored agency, Active Ageing programme. It is also pleasing to report some collaborators', deliverers' and service-users' have become systems thinkers.

\section{REFERENCES}

Barak (2006). The immune system and happiness. Autoimmunity Reviews. 5, 523-527.

Bernardo, L.M., Abt, K.L., Ren, D., and Bender, C., 2010. Self-reported exercise during breast cancer treatment. Cancer nursing [online], 33, 304-309.

Brown, J.C., John, G.M., Segal, S., Chu, C.S. and Schmitz, K.H., 2013. Physical activity and lower limb lymphedema among uterine cancer survivors. Medicine and science in sports and exercise [online], 45(11), 2091.

Castle, J. A. 1999. The Development of a Multiple Paradigm Methodology for Operations Strategy. PhD, University of Kent.

Castle, J. A. 1998b. CVAM as a Meta-methodology: Theoretical and Practical Progress, Operational Research Society Annual Conference, OR, 40. Lancaster: Lancaster University.

Checkland, P., Scholes, J. 1990b. Techniques in soft systems practice, Part 4: Conceptual model building revisited. Journal of Applied Systems Analysis, Vol.10, pp.39-43. 
Chen, H.M., Tsai, C.M., Wu, Y.C., Lin, K.C. and Lin, C.C., 2015. Randomised controlled trial on the effectiveness of home-based walking exercise on anxiety, depression and cancerrelated symptoms in patients with lung cancer. British journal of cancer [online], 112(3), 438-445.

Chen, F. Jing, Y. Hayes, A. \& Lee, J. (2013). Two concepts or two approaches? A bi-factor analysis of psychological and subjective well-being. Journal of Happiness Studies. 14 10331068.

Cormie, P., Pumpa, K., Galvão, D.A., Turner, E., Spry, N., Saunders, C., Zissiadis, Y. and Newton, R.U., 2013b. Is it safe and efficacious for women with lymphedema secondary to breast cancer to lift heavy weights during exercise: a randomised controlled trial. Journal of cancer survivorship [online], 7(3), 413-424.

Department of Health, 2016. A Five Year Forward View, London: Department of Health.

Department of Health, 2015. Cancer Healthcare for the Future, London, Department of Health.

Department of Health (2013). Health Behaviours and Wellbeing, London: Department of Health.

Diener, E., \& Chan, M. Y. (2011). Happy people live longer: Subjective well-being contributes to health and longevity. Applied Psychology: Health and Well-being 3, 1-43.

Evans, G. Hamerston, L. Cherrett, L. and Sadd, D. 2018. A systemic analysis of the effectiveness of cancer support services in the Southwest of England. In: Houqiang, L., eds. 2018 International Forum on Sports Economy and Regional Cooperation, Economy Cooperation and Community of Shared Future of Mankind, Exercise Rehabilitation and Great Health, Chengdu, Sichuan 5-6 ${ }^{\text {th }}$ June. Chengdu: Sichuan Academy of Social Sciences.

Fields, J., Richardson, A., Hopkinson, J. and Fenlon, D., 2016. Nordic walking as an exercise intervention to reduce pain in women with aromatase inhibitor associated arthralgia: a feasibility study. Journal of pain and symptom management [online], 1-12.

Flood, R. L. and Jackson, M. C. 1991. Creative Problem Solving: Total Systems Intervention, Chichester: Wiley.

Gautam, A.P., Maiya, A.G. and Vidyasagar, M.S., 2011. Effect of home-based exercise program on lymphedema and quality of life in female postmastectomy patients: pre-post intervention study. Journal of rehabilitation, research and development [online], 48(10), 1261-1268.

Jeffs, E. and Huit, M., 2015. Treatment and outcomes of head and neck oedema referrals to a hospital-based lymphoedema service. British journal of community nursing [online], S6-S13.

King, M. Renó, V. \& Novo. E. (2013). The concept, dimension and methods of assessment of human well-being within a socio-ecological context: A literature review. Social Indicator Research. 111. 
HM Government, 2015. Sporting Future: A New Strategy for an Active Nation, London: Her Majesty's Government.

HM Government, 2014. Moving More, Living More [online] London: Her Majesty’s Government. Available from

https://www.gov.uk/government/uploads/system/uploads/attachment_data/file/279657/movin g_living_more_inspired_2012.pdf [Accessed $2^{\text {nd }}$ May 2016]

HM Government, 2011. The Chief Medical Officers' Guidelines on Physical Activity [online] London: Her Majesty's Government. Available from

https://www.gov.uk/government/publications/uk-physical-activity-guidelines/ [Accessed $2^{\text {nd }}$ May 2016]

Irwin, M.L., Cartmel, B., Gross, C.P., Ercolano, E., Li, F., Yao, X., Fiellin, M., Capozza, S., Rothbard, M., Zhou, Y. and Harrigan, M., 2015. Randomized exercise trial of aromatase inhibitor-induced arthralgia in breast cancer survivors. Journal of clinical oncology [online], 33(10), 1104-1111.

Livingston, P.M., Craike, M.J., Salmon, J., Courneya, K.S., Gaskin, C.J., Fraser, S.F., Mohebbi, M., Broadbent, S., Botti, M. and Kent, B., 2015. Effects of a clinician referral and exercise program for men who have completed active treatment for prostate cancer: a multicentre cluster randomized controlled trial (ENGAGE). Cancer [online], 121(15), 26462654.

Lucas \& Diener (2015) Chapter 26; Personality and subjective wellbeing; current issues and controversies. In; Lucas, R.E.; Diener, Ed; In: APA handbook of personality and social psychology, Volume 4: Personality processes and individual differences. Mikulincer, M (Ed); Shaver, P. R. (Ed); Cooper, M. L (Ed); Larsen, R J. (Ed): American Psychological Association; p. 577-599. [Chapter], Database: PsycINFO.

Midgley, G. 2000. Systemic Intervention: Philosophy, Methodology and Practice of Contemporary Systems Thinking, London: Kluwer Academic and Plenum Publishers.

Midtgaard, J., Stage, M., Møller, T., Andersen, C., Quist, M., Rørth, M., Herrstedt, J., Vistisen, K., Christiansen, B. and Adamsen, L., 2011. Exercise may reduce depression but not anxiety in self-referred cancer patients undergoing chemotherapy. Post-hoc analys is of data from the 'Body \& Cancer' trial. Acta oncologica [online], 50(5), 660-669.

McNeely, M.L., Parliament, M.B., Seikaly, H., Jha, N., Magee, D.J., Haykowsky, M.J. and Courneya, K.S., 2008. Effect of exercise on upper extremity pain and dysfunction in head and neck cancer survivors. Cancer [online], 113(1), 214-222.

Mingers, J. 1997. Towards Critical Pluralism. In: J. MINGERS, A. A. G. (ed.) Multimethodology. Chichester: Wiley, 1997, pp.407-440.

Morrill, E, Brewer, N., O’Neill, S, Lillie, S., Dees. E., Carey, L, \& Rimer. K. (2008). The interaction of post-traumatic growth and post-traumatic stress symptoms in predicting depressive symptoms and quality of life. Psycho-Oncology, 17, 948-953. 
Public Health England, 2014. Everybody Active, Every Day, London: Public Health England.

Saarto, T., Sievänen, H., Kellokumpu-Lehtinen, P., Nikander, R., Vehmanen, L., Huovinen, R., Kautiainen, H., Järvenpää, S., Penttinen, H.M., Utriainen, M. and Jääskeläinen, A.S., 2012. Effect of supervised and home exercise training on bone mineral density among breast cancer patients. A 12-month randomised controlled trial. Osteoporosis international [online], 23(5), 1601-1612.

Sanne M, Lamers.A, Bolier.L , Westerhof.GJ , Smit.F, Bohlmeijer. E.T (2012) The impact of emotional well-being on long-term recovery and survival in physical illness: a metaanalysis.

Journal of Behavioural Medicine. 35:538-547.

Schickler.P (2005) Achieving health or achieving wellbeing? Learning in Health and Social Care. 4, 217-227.

Self A, Thomas J \& Randall C. (2012) Measuring National Well-being: Life in the UK 2012. UK Office for National Statistics.

Sport England, 2016. Towards An Active Nation Strategy 2016-2021, London: Sport England.

Schroevers.M, Kraaij.V and Garnefsk.N (2008) How do cancer patients manage unattainable personal goals and regulate their emotions? British Journal of Health Psychology. 13 :551562.

Stowell, F. and Welch, C. 2012. Systems Practice: Making Sense of Complex Problems, Chichester,UK: Wiley.

Weich S, Brugha T, King M, McManus S, Bebbington P, Jenkins R, Cooper C, McBride O, Stewart-Brown S. (2011) Mental Well-Being and Mental Illness: Findings from the Adult Psychiatric Morbidity Survey for England 2007. British Journal of Psychiatry. 199: 23-28.

Wenzel, J.A., Griffith, K.A., Shang, J., Thompson, C.B., Hedlin, H., Stewart, K.J., DeWeese, T. and Mock, V., 2013. Impact of a home-based walking intervention on outcomes of sleep quality, emotional distress, and fatigue in patients undergoing treatment for solid tumors. The oncologist [online], 18(4), 476-484.

Winters-Stone, K.M., Dobek, J., Nail, L., Bennett, J.A., Leo, M.C., Naik, A. and Schwartz, A., 2011. Strength training stops bone loss and builds muscle in postmenopausal breast cancer survivors: a randomized, controlled trial. Breast cancer research and treatment [online], 127(2), 447-456. 